\title{
A structural move analysis of abstract in electronic engineering articles
}

Abarghooeinezhad, Mahjoobeh

English Department, Najafabad Branch, Islamic Azad University, Najafabad, Iran (mahjoobe abarghooei@yahoo.com)

Simin, Shahla

English Department, Najafabad Branch, Islamic Azad University, Najafabad, Iran (shahlasimin@yahoo.com)

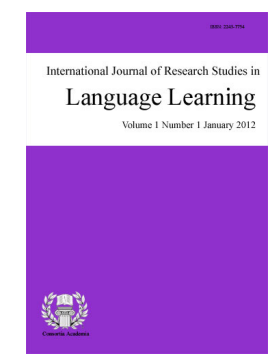

ISSN: 2243-7754 Online ISSN: 2243-7762

OPEN ACCESS

\section{Abstract}

Genre Analysis of academic and professional texts has been the great inspiration of much of ESP language description in the research articles, and as an important part, the abstract has gained significant attention from the academic communities mostly engineers. Following Swales's (1981) works on genre analysis, studies on different sections of research articles in various languages and fields abound, but only a few studies have been done in Iranian context. This study for the first time sought to recognize different rhetorical features of Moves in abstract section and draw a comparison between Iranian and Native English electronic engineers. To this end, 50 abstracts (25 IrIsI abstracts and $25 \mathrm{~N}-\mathrm{E}$ abstracts) published in international ISI journals in the area of electronic engineering during 2010-2014 were chosen and were analyzed based on genre analysis models proposed by Santos (1996) and AntMover software. The findings show that abstract section Moves as used by Ir and N-E do not completely correspond to the model proposed by Santos (1996). Moreover, some variations were observed between the Moves used by Ir and N-E. The findings may promise some implications for ESP pedagogy, syllabus design, and materials preparation.

Keywords: genre analysis; research article; abstracts; rhetorical moves; electronics 


\section{A structural move analysis of abstract in electronic engineering articles}

\section{Introduction}

For more than two decades genre analysis has received a lot of attention. The increasing interest in this discipline is motivated by a need to supply models of academic and scientific texts for the students, in order to produce those texts appropriately. In the same way, considerable attention has been given to this discipline by scholars in different areas, which made strong grip on discourse conventions an important factor. Besides, as Flowerdew (2013) mentioned, in order to evaluate the quality of academic contributions and have peer review, English is playing a leading role. However, he pointed out that English being recognized as lingua franca is the native language of a minority of scholars. This cause the majority of non-native authors great necessity to obtain particular knowledge of their register and genres in order to have successful academic publication (Flowerdew, 2013).

Therefore, Genre analysts have turned scholars' eyes to the nature of writing and attempt to understand different text structures. This fruitful area of research was thrived by John Swales, one of the powerful pioneers in this field. He probed the introduction section of research articles. He conducted the first genre-based analysis and asserted that the introduction section of articles follow a four-move model. He revealed that the introduction sections have the structure which consists of multiple sub-moves or Steps (Lakic, 1997). Later, he revised his model to a three-move pattern due to the existence of several criticisms based on move 1 and move 2 separations difficulty. Swales (1981, 1990) labeled his Move1-3, establishing a territory, establishing a niche and occupying a position respectively. However, Lakic (1997) argued that "the choice between 3-move and 4-move model primarily depends on the discipline" (p. 410).

\subsection{Moves Definition}

Swales (2004) defines Move in genre analysis as "a discoursal or rhetorical unit that performs a coherent communicative function in a written or spoken discourse" (Swales, 2004, p. 29). As Swales (2004) pointed out, "a Move, at one extreme, can be realized by a clause; at the other by several sentences. It is a functional not a formal unit" (p. 20). Ding's definition of Move in English for Academic Purposes (EAP) writing genres can be interpreted as "a functional unit in a text, being related to the overall task, which is used to identify the textual regularities in certain genres of writing" (Ding, 2007, pp. 369-370). Based on what he said, Moves can have different ranges from one proposition to multiple paragraphs. Moreover, Nwogu (1997) defines Move as "a text segment made up of a bundle of linguistic features (lexical meaning, propositional meanings, illocutionary forces, etc.) which give the segment a uniform orientation and signal the content of discourse in it" (p. 122).

Since Swales' (1981) work on introduction of research articles, abundant scholars have investigated rhetorical features of articles different sections. For instance, Brett (1994) and Williams (1999) tried to explore Results section features and Hopkins and Dudley-Evans (1988) following by Holmes (1997), Fallahi and Erzi (2003) evaluated the Discussion section. Meanwhile, abstract as one of the most crucial parts of research articles has gain a lot of attention. This single paragraph which precedes the article provides the readers with the necessary information, without any need to cover the whole paper; hence, the abstract is a critical element of the research paper which can determine the acceptance or rejection of an article for conferences. As Van Bonn and Swales (2007) mentioned, the abstracts are mostly between 100-250 words in which the principle elements and research findings are included. By the same token, engineers have shown considerable interests in move-pattern in abstract writing.

Engineers attempt to present their theoretical perspectives as well as specific applications in international journals and conferences. Thus, well-prepared and comprehensive abstract seems crucial in order to be published. 
A structural move analysis of abstract in electronic engineering articles

Engineering Abstracts frequently contain facts, figures, and discoveries that should be in compact form and easy to absorb key facts in a fraction of the time. Therefore, engineers have put a lot of effort into mastering the conventional structure of different sections, particularly abstract in technical writing. Consequently, using genre as a basis for an investigation of engineering discourse would be able to reveal how the technical papers are structured.

\section{Background}

Like different other sections, variation of rhetorical move pattern in abstract section has been observed. For instance, Huckin (2001) revealed that stating the purpose in abstracts of medical articles is not included as a move. Moreover, Kanoksilapatham (2007) showed that there is much more tendency (double) in biochemistry papers to announce principal outcome rather than microbiology. However, these differences as Bhatia (1993) announced, could be due to various communicative aims in multiple genre which signals the great attention for continues examination and development. By considering the insufficiency of Swales' (1981) CARS model, Santos' (1996) proposed his five-move pattern with an obvious purpose (see Appendix A).

As seen in Appendix A, Santos (1996) suggested that a thorough abstract, needs to be composed of five different Moves. He labeled them as followed: Move1 (STR) Situating the research that provides the readers with the current research background, Move2 (PTR) presenting the research in which the study objectives and research questions are mentioned. After that, Move3 was introduced. This Move is labeled as (DTM) describing the methodology that explained the materials and variables being employed in the study. Next, Move4 (STF) summarizing the findings is followed by the final Move (DTR) discussing the research. In this ending Move, the results are discussed and some recommendation and implications are provided. Santos (1996) by analyzing ninety-three Applied Linguistics articles, explained that Move2, Move3 and Move4 are almost used by authors. Eighty percent of the corpus mentioned Move 5 while only $43 \%$ decided to use Move1.

In addition, Santos (1996) the same as Swales (1981) had his own followers. For instance, Pho (2008) carried out a research based on Santos' (1996) pattern in applied Linguistics abstract sections and also Educational Technology. His findings mostly agreed with what Santos had previously pointed out. Pho (2008) expressed that almost all abstracts included in his corpora, employed Move2 to Move5. Comparing the final results revealed that Move2, Move3 and Move4 where considered as obligatory Moves while Move1 as an optional elements had been used by corpus authors. The above mentioned studies indicate the existence of a particular model in the abstract sections that seems Iranian scholars is not familiar with such convention. To date, regarding genre-based, various studies in Iranian context have been done in order to comprehend the nature of the medical and applied linguistic RAs (Falahati, 1994; Mohammadi khahan, 2006; Faghih \& Rahimpour, 2009; Bahrami \& Riazi, 2009; Rezaee \& Sayfouri, 2010 and Marefat \& Mohammadzadeh, 2013); however, from a genre-analytic perspective, no study has investigated the norms and conventions of engineering articles abstract, particularly electronic engineering. To this end, this study will attempt to seek answers to the following questions:

$>\quad$ What are the rhetorical moves usage frequencies in the abstracts of IrIsI \& N-E IsI articles in the field of electronic engineering?

$>\quad$ Is there any significant difference between IrIsI and N-E IsI articles based on every individual Move/Sub-Move usage frequencies in their abstract section?

$>\quad$ What are the obligatory (or key) and optional Moves in the abstracts sub-genre of IrIsI \& N-E IsI articles in the field of electronic engineering?

\section{Methodology}

\subsection{Corpus Procedures}

The corpus of this study consists of a total of 50 abstracts (25 IrIsI abstracts and 25 N-E abstracts) Research Article abstracts in the field of electronic engineering published in ISI journals by Iranian and native-English 
Abarghooeinezhad, M., \& Simin, S.

scholars between 2010 and 2014. Journals with the international reputation and easy online accessibility among the top ones with the highest impact factor in the discipline of Electronic engineering were selected. These journals which have been registered by ISI (recently Thompson Reuters), are leading journals in their academic societies and publications in the journals are widely cited in electronic field. First of all, a comprehensive list of journals was collected. After that thirty-three were selected by consulting the expert in the field of electronic engineering. Later, in order to facilitate the selection process Native and Non-Native (Iranian) authors of the suggested journals were categorized separately.

For the Native-English category, articles were checked in terms of nationalities of their authors, therefore all writers were asked whether English is their first language or not through e-mail. At last, 25 abstracts from each category were randomly selected. To do a precise analysis and in order to be able to use AntMover software, articles were grammatically analyzed and ones with no grammatical derivation were used.

\subsection{Instrumentation}

Two types of instrumentations were utilized:

1. AntMover software (developed by Laurence Anthony 2003) - AntMover which is a text structure analyzer software, can be easily available on Internet. While the text file is opened the user can choose up to four view of the file.

$>\quad$ The original text without any analysis;

$>\quad$ The text which has been separated into sentences;

$>\quad$ Text different sentences with rhetorical labels;

$>$ Outline view of the rhetorical features.

Regarding the move/sub-moves recognition, all the corpus abstracts were imported into the program.

2. Santos's (1996) five-move-pattern - This framework is designed for human coders. Human coders can use the Steps or Sub-Moves and the Moves depicted in this framework for the analysis of moves and steps in 'abstract' corpus; it is important that frequencies and percentages for each move be found, and the results be used as the data. Human coders can also use such linguistic features as words, structures, hedging devices, and citations for the identification of Moves and Steps. They can also closely read each text and use such organizational clues as headings and subheadings for identifying moves and steps. Here it should be pointed out that Santos' (1996) framework due to its comprehensive structures which is because of specified questions has been opted for the structural analysis. Moreover, this pattern has been employed by multiple scholars such as Graetz (1985), Bhatia (1993) and Pho (2008).

\subsection{Procedure}

After collecting the entire corpus, each text/abstract was assigned a unique code (e.g., AB\#1, AB\#2, $\mathrm{AB} \# 3$... AB\#50). In the next step a set of analyses was performed. A frequency count was performed to identify the total number of words in each abstract. Then each abstract was saved as a *txt file to be submitted for move analysis to the AntMover. A structural Move analysis was also conducted by two human coders who were separately coding each abstract and identified the moves. They labeled the moves according to the model proposed by Santos'(1996) framework for abstract analysis. Then a meeting was held, and labeled Moves by human coders and software outputs were compared. However, if any mismatches or difference in coding couldn't be resolved through extensive discussion, it had been agreed to ask a third coder.

\subsection{Inter-coder Agreement (Reliability)}

To avoid subjectivity, two coders were participating in the current study (the researcher herself and a Ph.D. researcher). Coders were asked to identify the Moves based on Santos (1996) model while they were completely informed of labeling. Coding process was carried out independently. Inter -coder reliability was determined by 
A structural move analysis of abstract in electronic engineering articles

comparing the coders output. Records for each abstract were done move by move, agreements and disagreements on the presence and absence of each move were also noted. If the copies of the same abstracts, which had been marked separately by the two coders were identical in terms of Move (or Moves), they were determined as agreement. Otherwise, there were disagreements on the structure of Moves. After that, in order to be able to categorize Moves and Move sequences for all the abstracts, in the case of disagreement, a meeting was held by the two coders. This was done to provide a chance for coders to come to a maximally acceptable index. As it was evident that satisfactory inter-coder agreement couldn't be easily achieved, the abstract's text file was submitted in Antmover software which was explained above.

At last, Antmover identified Move was counted as an agreed Move. Finally the frequency of occurrence for each move was counted and categorized for each abstract. An inter-rater reliability analysis using the Kappa statistic was performed to determine consistency among raters. However, this reliability was performed only on Move4 and Move5 due to complete agreement on other Moves, and as a result the average of it was announced as a final result. Table 1 and Table 2 present the inter-rater reliability (Kappa) between two coders in Move 4 and 5 , respectively.

\section{Table 1}

The Result of an Inter-Rater Reliability Analysis of Move4

\begin{tabular}{|c|c|c|c|c|c|}
\hline Approx. Sig. & Approx. $\mathrm{T}^{\mathrm{b}}$ & $\begin{array}{l}\text { symp. Std. } \\
\text { Error }^{\mathrm{a}}\end{array}$ & Value & & \\
\hline .000 & 5.464 & .110 & $\begin{array}{c}.767 \\
50\end{array}$ & Kappa & $\begin{array}{l}\text { Measure of Agreement } \\
\mathrm{N} \text { of Valid Cases }\end{array}$ \\
\hline
\end{tabular}

Note. a. Not assuming the null hypothesis. b Using the asymptotic standard error assuming the null hypothesis

Table 2

The Result of an Inter-Rater Reliability Analysis of Move5

\begin{tabular}{|c|c|c|c|c|c|}
\hline Approx. Sig. & Approx. $\mathrm{T}^{\mathrm{b}}$ & $\begin{array}{l}\text { Asymp. Std. } \\
\text { Error }^{\mathrm{a}}\end{array}$ & Value & & \\
\hline .000 & 5.071 & .100 & $\begin{array}{c}.712 \\
50\end{array}$ & Карра & $\begin{array}{l}\text { Measure of Agreement } \\
\mathrm{N} \text { of Valid Cases }\end{array}$ \\
\hline
\end{tabular}

Note. a. Not assuming the null hypothesis. b. Using the asymptotic standard error assuming the null hypothesis

Based on the above Tables, the inter-rater reliability for the coders in Move4 was found to be Kappa $=0.767$ $(p<.0 .001)$, and Kappa=0.712 for Move5. While we had the complete agreement on the other Moves/Sub-Moves the total Kappa which is the average of $0.767,0.712$ and eight ones for each eight other Sub-Moves will be 0.95 . This is an almost perfect agreement based on Table 3 provided by Landis and Koch (1977).

Table 3

The Kappa Interpretation

\begin{tabular}{cc}
\hline Kappa & Interpretation \\
\hline$<0$ & Poor agreement \\
$0.0-0.20$ & Slight agreement \\
$0.21-0.40$ & Fair agreement \\
$0.41-0.60$ & Moderate agreement \\
$0.61-0.80$ & Substantial agreement \\
$0.81-1.00$ & Almost perfect agreement \\
\hline
\end{tabular}

\section{Results}

\subsection{The Rhetorical Moves Frequency}

In order to answer the first research question which is interested in finding the frequencies of rhetorical Moves usage of Iranian ISI articles in the abstracts sections and N-E ISI articles in the field of electronic 
Abarghooeinezhad, M., \& Simin, S.

engineering the average of each Move and Sub-Move of two groups were computed. After that, the observed Move frequencies in the current study were specified and a comparison was drawn between the average of each Move and Sub-Move of two groups which is shown in Figure 1.

\section{Table 4}

The N-E Sub-Moves Frequencies

\begin{tabular}{cccccccccccc}
\hline Frequency & $1 \mathrm{~s} 1 \mathrm{~A}$ & $1 \mathrm{~s} 1 \mathrm{~B}$ & $1 \mathrm{~s} 1 \mathrm{C}$ & $1 \mathrm{~s} 2$ & $2 \mathrm{~s} 1 \mathrm{~A}$ & $2 \mathrm{~s} 1 \mathrm{~B}$ & $2 \mathrm{~s} 2$ & 3 & 4 & $5 \mathrm{~s} 1$ & $5 \mathrm{~s} 2$ \\
\hline $\mathrm{N}$ & 13 & 1 & 0 & 2 & 22 & 0 & 1 & 22 & 18 & 9 & 3 \\
$(\%)$ & 52 & 4 & 0 & 8 & 88 & 0 & 4 & 88 & 72 & 36 & 0 \\
\hline
\end{tabular}

Table 5

The Ir Sub-Moves Frequencies

\begin{tabular}{cccccccccccc}
\hline Frequency & 1S1A & 1S1B & 1S1C & $1 \mathrm{~S} 2$ & 2S1A & 2S1B & $2 \mathrm{~S} 2$ & 3 & 4 & $5 \mathrm{~S} 1$ & $5 \mathrm{~S} 2$ \\
\hline $\mathrm{N}$ & 12 & 0 & 2 & 1 & 21 & 7 & 0 & 24 & 22 & 8 & 2 \\
$(\%)$ & 48 & 0 & 8 & 4 & 84 & 28 & 0 & 96 & 88 & 32 & 8 \\
\hline
\end{tabular}

Findings indicate that Iranian authors mostly used Move2 (100\%) followed by Move3 (96\%) and Move4 $(88 \%)$. As for the Native English writers, Move2 and Move3 recorded the highest frequency of use (88\%) and after that Move4 was highly used (72\%). Recommending by Santos (1996) and Pho (2008), a Move with 80\% occurrence or more will be regarded as an obligatory move, and less than that will be considered optional. Therefore, as suggested by the findings, Iranian engineers considered Move 2, Move 3 and Move 4 as obligatory moves while Native English ones didn't include Move 4 as an obligatory Move. From their perspectives, Move 2 followed by Move 3 was only considered as obligatory Moves.

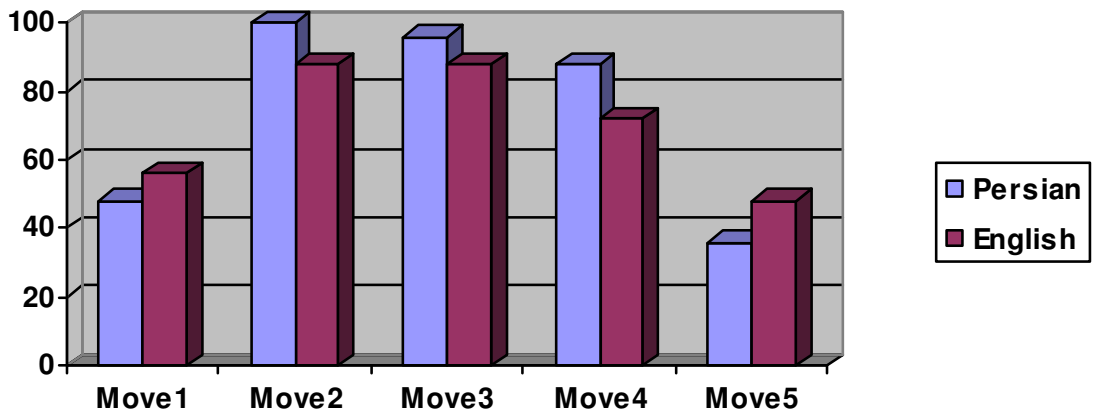

Figure 1. Moves frequency

Along with variety in usage frequency of structural moves between the two groups of authors, the text length was different, too. The shortest abstract employed only 28 words, while the longest one had 275 words.

\subsection{IrISI and N-E ISI Moves and Sub-Moves differences}

In order to compare and investigate any significant differences between IrIsI and N-E IsI articles based on every individual Move/Sub-Move usage frequencies in their abstract section five chi-square tests were carried out. These tests were applied on each Moves/sub-Moves of the abstract sections individually. The first set (Table6) illustrates the results of chi-square tests applied on Move1- Move5. The Table shows that the differences between the frequencies of the two groups' uses of levels of significance for Move1, Move2, Move3, Move4 and Move5 of the abstract section are respectively are $0.571,0.149,0.297,0.157$ and 0.390 ( $p>0.05$ for all the tests) which does not demonstrate any significant differences between the groups. Not significantly different because the levels of significance are $0.571,0.149,0.297,0.157$ and 0.390 , respectively $(p>0.05$ for all the tests). 
Table 6

Results of IrISI chi-square tests for the Move1-Move5

\begin{tabular}{ccccc}
\hline & \multicolumn{3}{c}{ Frequency } & \\
\cline { 2 - 4 } Move & Ir & N-E & $\chi^{2}$ & Asymp.Sig. \\
\hline 1 & 12 & 14 & .321 & .571 \\
2 & 25 & 23 & 2.083 & .149 \\
3 & 24 & 22 & 1.087 & .297 \\
4 & 22 & 18 & 2.000 & .157 \\
5 & 9 & 12 & .739 & .390 \\
\hline
\end{tabular}

The next Table shows that the differences between Move1Sub-Move1A, Sub-Move1B, Sub-Move1C and Move1Sub-Move2 usage frequencies among the two groups of the abstract section with different levels of significance, $0.777,0.312,0.149$, and 0.552 , respectively ( $p>0.05$ for all the tests) which does not reveal any significant differences.

Table 7

Results of IrISI and N-E ISI chi-square tests for the Move1Sub-moves

\begin{tabular}{|c|c|c|c|c|}
\hline \multirow[b]{2}{*}{ Sub-Move } & \multicolumn{2}{|c|}{ Frequency } & \multirow[b]{2}{*}{$\chi^{2}$} & \multirow[b]{2}{*}{ Asymp.Sig. } \\
\hline & $\mathrm{Ir}$ & $\mathrm{N}-\mathrm{E}$ & & \\
\hline $1 \mathrm{~A}$ & 12 & 13 & .080 & .777 \\
\hline $1 \mathrm{~B}$ & 0 & 1 & 1.020 & .312 \\
\hline $1 \mathrm{C}$ & 2 & 0 & 2.083 & .149 \\
\hline 2 & 1 & 2 & .355 & .552 \\
\hline
\end{tabular}

The result of next chi-square test is provided in Table 8. This Table which investigated Move2 Sub-Moves for goodness of fit reveals that the levels of significance for Move2 Sub-Moves 1A, 1B, 2 are, respectively, $0.684,0.004$, and 0.312 ( $p>0.05$ ). The differences are, except Sub-Move 1B, not significant.

\section{Table 8}

Results of IrISI and N-E ISI chi-square tests for the Move2Sub-Moves

\begin{tabular}{|c|c|c|c|c|}
\hline \multirow[b]{2}{*}{ Sub-Moves } & \multicolumn{2}{|c|}{ Frequency } & \multirow[b]{2}{*}{$\chi^{2}$} & \multirow[b]{2}{*}{ Asymp.Sig } \\
\hline & Ir & $\mathrm{N}-\mathrm{E}$ & & \\
\hline $1 \mathrm{~A}$ & 21 & 22 & .166 & .684 \\
\hline $1 \mathrm{~B}$ & 7 & 0 & 8.140 & $.004 *$ \\
\hline 2 & 0 & 1 & 1.020 & .312 \\
\hline
\end{tabular}

The results of the other Chi-Square tests, which have been applied on the frequencies of the Moves 3 and Move4 of the two groups, have been showed in Table 9. As it can be seen in this Table, no significant differences between Move3 and Move4 with significance levels, respectively, 0.297, and 0.157 ( $p>0.05)$ were observed.

Table 9

Results of IrISI and N-E ISI chi-square tests for the Move3 and Move4

\begin{tabular}{ccccc}
\hline & \multicolumn{3}{c}{ Frequency } & \\
\cline { 2 - 4 } Moves & Ir & N-E & $\chi^{2}$ & Asymp.Sig. \\
\hline 3 & 24 & 22 & 1.087 & .297 \\
4 & 22 & 18 & 2.000 & .157 \\
\hline
\end{tabular}

At last, the following test results with the value of 0.765 and 0.637 showed that Iranian and Native-English writers regarding the Move5Sub-move1 and Sub-Move2 usage frequencies have no significant differences. 
Abarghooeinezhad, M., \& Simin, S.

\section{Table 10}

Results of IrISI and N-E ISI chi-square tests for the Move5Sub-Moves

\begin{tabular}{ccccc}
\hline & \multicolumn{3}{c}{ Frequency } & \\
\cline { 2 - 5 } Sub-Moves & Ir & N-E & $\chi^{2}$ & Asymp.Sig. \\
\hline 1 & 8 & 9 & .89 & .765 \\
2 & 2 & 3 & .222 & .637 \\
\hline
\end{tabular}

By considering the result of recent chi-square tests mentioning above, our Null Hypothesis is partly rejected. This rejection is because of the existence of a significant difference between the two groups usage frequencies of Move2Sub-Move1B.

\section{Discussion of Findings}

By comparing the rhetorical features of Iranian and Native-English ISI articles and tabulating the usage frequencies of each individual Move/Sub-Move, a close similarity was concluded. This reveals that in spite of minor varieties, the two Iranian and Native-English authors were able to develop their research papers and utilize these specific moves. However, these superficial similarities in Abstract section used by Iranian and Native-English authors who were randomly selected from ISI journals stated that both groups were successful in terms of expressing necessary types of information. Although, this study is one of the first research in engineering field, comparing it with Atai and Falah's (2005) as well as Rezaee and Sayfouri's (2010) study in medicine, show that Iranian scholars in engineering the same as their counterparts in medicine regarding the standard native-like move usage performed better than linguistics authors.

As it has been said above, findings revealed that the Iranian authors have a much more tendency (100\%) to use Move2 followed by Move3 (96\%) and Move4 (84\%). As for the N-E writers, Move2 and Move3 recorded the highest frequency of use and with the similar frequency of occurrence $(88 \%)$. Therefore, these Moves are considered as obligatory Moves. This is due to Santos (1996) and Pho (2008) suggestion that a Move with $80 \%$ occurrence or more will be regarded as an obligatory move, and Moves less than that would be considered optional. Regarding Ir and N-E point of view, Move1 and Move 5 are considered as optional Moves for both groups; however N-E authors had more tendency to employ them. In Move1 author tries to provide orientation to the reader in relation to where the writer is coming from while motivating the reader to examine the research to be reported. The writer chooses to begin his abstract by providing some background knowledge in order to situate his research and relate his study to the existent objectives. In Move5, the same phenomenon occurred again. Move5 provides situation in which the researcher can advance the significance of his/her work, i.e., to make claims relative to the value or implication of the results obtained. In this ending Move, writer has the chance of discussing the research by evaluating the findings and linking the reported research back to the broad research field. While Iranian authors tend to use Move5 less than Native-English ones, their reader's journey through the abstract ends with a touch of mystery tour.

Iranian writers seem unable to attempt to convince their readership that their research has potential usefulness which can be a turn-off for the reader for decision-making purposes. This could suggest that, Iranian writers are not too concern about disclosing their findings or discussing their research. Moreover, these differences between these two groups can be due to Iranian lack of English general knowledge. The low level of English proficiency limits their comprehension. As a result, they failed to present adequate types of information in their first and last Moves which required considerable writing skill. At last, having less tendency of using Move1 and Move5 by Iranian writers than the Native-English ones may be because insufficient knowledge of Move structures. It is possible, the fact that some percentage of Iranian authors compared to Native-English ones had fewer uses of Move1 (Situating the Research) and Move5 (Discussing the Research) is because they follow peers RA's abstracts pattern. In a specific abstract, Move1 or even Move5 being neglected by the writer during organizing his/her abstract, cause many other abstracts to be treated similarly by others. 
A structural move analysis of abstract in electronic engineering articles

One of the results of this study showed that Move2 and Move3 were the most frequent Moves in both Ir and N-E Abstracts. This finding is in line with Santos (1996) study. In fact, Move2 (Presenting the research) consisting three Sub-Moves (1A- Indicating Main Features, 1B Indicating Main Purpose, 2 Hypothesis Raising) along with Move3 (Describing the Methodology) being highly performed $(100 \%, 96 \%)$ by Iranian authors almost the same as Native-English ones $(88 \%, 88 \%)$ revealed that Ir writers know the great importance of presenting the research by indicating main features and purposes of the study. Nevertheless, Sub-Moves interpretation provides different rhetorical Move usage design.

This study clarifies that although overall similarities were observed between Ir and N-E authors Move2Sub-Move1B has been presented differently. This Sub-Move has meaning fully been treated differently by two groups of Ir and N-E. While 28 percent of Iranian authors employed Move2Sub-Move1B which deals with indicating main purpose of the study no evidence were reported in N-E corpora. More uses of Move2Sub-Move1B indicate that significantly more attention has been given to outlining articles main purposes by Ir group. In RAs, Iranian authors seem to believe that in order to propose their research, exact aims should be directly marked in their abstract. However, N-E ones do not feel the same. From Native-English point of view, research goal can clearly be interpreted from descriptive Sub-Moves being employed in their abstract sections and no purposive statement is requisite.

\section{Conclusions and Implications}

This study sought to discover the rhetorical Move usage frequencies in the Abstract section of IrISI and N-E ISI articles in the field of electronic engineering. This research was conducted to explore what Move structures could be found in this part and to discover differences and similarities between the two groups. The identification of Moves was performed using Santos' model (1996). Based on the above-presented discussion, except Move2Sub-Move1B, no significant differences were reported between the two groups under investigation. Besides, the obligatory Moves (Move2 \& Move3) observed in this study completely followed what Santos tentatively proposed.

On the contrary, these findings are not in line with those of San and Tan (2012) study of computer and communication systems abstract. They identified that while some Moves were employed by published papers, they didn't follow the specific model (San \& Tan, 2012). As they suggested which was retrieved from their findings, Santos' five-Move pattern in abstract writing may not be the norm for abstract writing in the field of engineering. This is evident in distinguishing and differentiating Move4 from Move5 which turned to one of the most arduous part of Move analysis phase. As it is proposed by this study, engineering articles abstract, electronic in particular seems to utilize the combination of these Moves, which is recommended to be named as Research Evaluation. Electronic conclusion is a synthesis of the information from researchers' suggested system and most of the time simulation outputs which corroborate each other. Besides, the findings revealed that only a relatively small proportion of both Iranian and Native-English authors applied all five Moves proposed by Santos which signals Santos disability of predicting engineering RAs Abstracts. In conclusion to help remedy Santos' model deficiency, this study suggests the following pattern for engineering and electronic engineering abstracts in particular.

\section{The Suggested Move Pattern}

Move1 Situating the Research

(Sub-Move1)Stating background knowledge

(Sub-Move2)Sating previous studies deficiency

Move2 Presenting the Research

(Sub-Move1)Stating research main features

Move3 Describing the methodology

Move4 Evaluating the Research

(Sub-Move1) mentioning the result obtained from theory and simulation (if simulation was performed) 
Abarghooeinezhad, M., \& Simin, S.

From the theoretical point of view, analyzing Abstracts from the perspective of genre make extensive contribution to the knowledge about Move patterns in the Iranian context. This analysis strived to identify engineering generic components and regularities of form and content with the purpose of providing language learners with tentative model of communication in this genre. This study partially satisfies its main goal, and it just raises other questions and hypotheses on the issue in the reader's mind in addition to the addressed research questions. A pedagogical suggestion, based on this study, would be that academic writing instructions be aware of the standard move structure of Abstract subgenre and directly tell their students that such Moves are to be included in their research articles abstracts. In order to achieve such goals, as stated by Simin et al. (2014), by explicit instruction and raising awareness English teachers and more specifically EAP teachers can greatly assist their students of rhetorical importance of this genre and the ways they can structure their Abstracts. Thus, familiarizing the students with the Abstract section of electronic engineering field enables them to organize their own Abstracts without gaining ideas from other articles Abstracts. In this regard, effective instruction can assist learners not only to start and write their articles Abstracts, but also to make them familiar with the importance of this genre, so they will write it with more care and attention in the future.

\section{References}

Anthony, L. (2003). Ant Mover. Retrieved from http://www.antlab.sci.waseda.ac.jp/software.html

Atai, M. R., \& Falah, S. (2005). A contrastive genre analysis of result and discussion sections of applied linguistic research articles written by native and nonnative English speakers with respect to evaluated entities and ascribed values. Paper presented at the Tenth International Conference on Sociolinguistics Moderator, Edinburgh, Scotland. Retrieved from http://www.paaljapan.org/resources/proceedings/PAAL10/pdfs/atai.pdf

Bahrami, A. \& Riazi, A. (2009, October). Iranian scholars and scientific publications in English: Attitudes, problems and strategies. Teaching English Language and Literature Society of Iran, 3(11), 33-59.

Bhatia, V. (1993). Analyzing genre: Language use in professional settings. New York: Longman.

Ding, H. (2007). Genre analysis of personal statements: Analysis of moves in application essays to medical and dental schools. English for Specific Purposes, 26, 368-392. http://dx.doi.org/10.1016/j.esp.2006.09.004

Faghih, E., \& Rahimpour, S. (2009). Contrastive rhetoric of English and Persian written text: Metadiscourse in applied linguistic research articles. Rice Working Papers in Linguistic, 1, 92-107.

Falahati, R. (1994). The use of hedging across different disciplines and rhetorical sections of research articles. Paper presented at the $22^{\text {nd }}$, International Conference on East Asian Linguistics (ICEAL2), Vancouver, Canada. Retrieved from http://www.sfu.ca/content/dam/sfu/linguistics/Gradlings/NWLC_Proceedings/falahati99-112.pdf

Fallahi, M. M., \& Erzi, M. (2003). Genre analysis in language teaching: An investigation of the structure of the discussion section of language-teaching-journal articles. IJAL, 6(1), 69-81.

Flowerdew, J. (2013). Some thoughts on English for Research Publication Purposes (ERPP) and related issues. Retrieved from http://journals.cambridge.org/abstract_S0261444812000523

Graetz, N. (1985). Teaching EFL students to extract structural information from abstracts. In J. M. Ulign, \& A.K. Pugh (Eds.), Reading for professional purposes: Methods and materials in teaching languages (pp. 123-135). Leuven: Acco.

Holmes, R. (1997). Genre analysis and the social sciences: an investigation of the structure of research article discussion sections in three disciplines. English for Specific Purposes, 16(4), 321-377. http://dx.doi.org/10.1016/S0889-4906(96)00038-5

Hopkins, A., \& Dudley-Evans, T. (1988). A genre-based investigation of the discussion sections in articles and dissertations. English for Specific Purposes, 7, 113-121. http://dx.doi.org/10.1016/0889-4906(88)90029-4

Huckin, T. N. (2001). Abstracting from abstracts. In M. Hewings (Ed.), Academic writing in context (pp. 93-103). Birmingham: University of Birmingham Press.

Kanoksilapatham, B. (2007). Rhetorical Organizations of Research Article Introductions in Biochemistry and 
Microbiology. ESP Malaysia. A Journal on English for Specific Purposes, 13(2), 21-37.

Lakic, I. (1997). Genre analysis of article introductions in economics. ASP, 15(18), 409-426. http://dx.doi.org/10.4000/asp.3239

Marefat, H. \& Mohammadzadeh, S. (2013). Genre analysis of literature research article abstracts: A cross-linguistic, cross-cultural study. Applied Research on English Language, 2(2), 37-50.

Mohammadi Khahan, F. (2006). A contrastive analysis of the frequency and types of hedges and boosters used in Results and Discussion sections of medical and applied linguistics research articles written by PNS and ENS researchers. Unpublished MA thesis, University of Teacher Education, Tehran, Iran.

Nwogu, N. K. (1997). The medical research paper: structure and functions. English for Specific Purposes, 16(2), 119-138. http://dx.doi.org/10.1016/S0889-4906(97)85388-4

Pho, P. D. (2008). Research article abstracts in applied linguistics and educational technology: A study of linguistic realizations of rhetorical structure and authorial stance. Discourse Studies, 10(2), 231-250. http://dx.doi.org/10.1177/1461445607087010

Rezaee, A., \& Sayfouri, N. (2010). Iranian 1SI and non-1SI medical research articles in English: A comparative ESP/EAP move analysis. Journal of English Language Teaching and Learning, 52(212), 135-160.

San, L., \& Tan, H. (2012). A comparative study of the rhetorical moves in abstracts of published research articles and students' term papers in the field of computer and communication systems engineering. International Journal of Applied Linguistics \& English Literature, 1(7), 40-50. http://dx.doi.org/10.7575/ijalel.v.1n.7p.40

Santos, M. B. D. (1996). The textual organization of research paper abstracts in applied linguistics. Text, 16, 481-499.

Simin, S., Eslami, Z. R., Eslami-Rasekh, A., \& Ketabi, S. (2014). The effect of explicit teaching of apologies on Persian EFL learners' performance: When e-communication helps. International Journal of Research Studies in Language Learning, 3(4), 71-84. http://dx.doi.org/10.5861/ijrsll.2014.661

Swales, J. M. (1981). Aspects of article introductions. Aston ESP Research Reports No. 1, Language Studies Unit, University of Aston in Birmingham, UK.

Swales, J. M. (1990). Genre analysis. English in academic and research settings (pp. 20-29). Cambridge: Cambridge University Press.

Swales, J. M. (2004). Research genres: Explorations and applications. Cambridge: CUP. http://dx.doi.org/10.1017/CBO9781139524827

Van Bonn, S., \& Swales, J. (2007). English and French journal abstracts in language sciences: Three exploratory studies .Journal of English for Academic Purposes, 6, 93-108. http://dx.doi.org/10.1016/j.jeap.2007.04.001

Williams, I. (1999). Results sections of medical research articles: Analysis of rhetorical categories for pedagogical purposes. English for Specific Purposes, 18, 347-366.

http://dx.doi.org/10.1016/S0889-4906(98)00003-9 


\section{Appendix A}

Santos' (1996) Framework for Abstract Analysis

Moves Function/Description Question asked

Move 1: Situating the research

Setting the scene for the current

What has been

Research (topic generalization) known about the field/topic of research?

$<$ STR $>$

Move 2: Presenting the research

Stating the purpose of the study, What is the study

Research questions and/or hypotheses about?

$<$ PTR $>$

Move 3: Describing the Describing the materials, subjects,

How was the Variables, procedures research done?

methodology $<$ DTM $>$

Move 4: Summarizing the Reporting the main findings of the

What did the Study researcher find?

findings $<\mathrm{STF}>$

Move 5: Discussing the research

Interpreting the results/findings

What do the results

$<$ DTR $>$ And/or giving recommendations mean?

Implications/applications of study So what? 